\title{
A Rare Presentation of an Oro-Antral Communication after Trimble's Modification of Lefort I Osteotomy
}

\author{
${ }^{1}$ Manikandhan Ramanathan, ${ }^{2}$ Senthil Nathan, J.Godwin Alex Kiruba ${ }^{3}$ \\ IProfessor, Department of Oral and Maxillofacial Surgery, Meenakshi Ammal Dental College and Hospital, \\ MAHER University, Chennai- 600095, Tamilnadu, India. ${ }^{2}$ Assistant Professor, Department of Dentistry, \\ Meenakshi Medical College and Hospital, MAHER University, Chennai- 600095, Tamilnadu, India. ${ }^{3}$ Surgical \\ Fellow, Meenakshi Cleft and Craniofacial Centre, MAHER University, Chennai- 600095, Tamilnadu,India
}

\begin{abstract}
Lefort I osteotomies are one of the most commonly performed surgeries in the maxillofacial spectrum. There had been reports of umpteen number of complications after Lefort I ostetomy. The authors present a case of an oro-antral communication after Trimble's modification of Lefort I osteotomy, which has not been published before in the English literature.
\end{abstract}

Keywords: "Oro-antral communication, Trimble's technique, Lefort I osteotomy, Buccal advancement flap, Buccal pad of fat."

\section{Introduction}

Le Fort I osteotomies are routinely employed in the correction of various dentofacial deformities. They are associated with a wide number of complications ranging from an abscess to total unilateral blindness ${ }^{[1]}$. Occurrence of oro-antral fistulas are a rare complication after Lefort I osteotomies and there has been no report in the English literature documenting the occurrence of an oro-antral fistula after Trimble's modification of Lefort I osteotomy.

The authors present a case of oro-antral fistula after Trimble's procedure, with explanation of the probable etiologic factor and its management.

\section{Corresponding Author:}

\section{Dr. J. Godwin Alex Kiruba MDS}

Surgical Fellow, Meenakshi Cleft and Craniofacial

Centre, MAHER University, Chennai- 600095,

Tamilnadu, India

e-mail: drgodalba@gmail.com
Case Report: A 24year old male patient who reported to Meenakshi Ammal Dental College and Hospital was examined and diagnosed with midface hypoplasia, vertical maxillary excess and mandibular prognathism. After pre-surgical orthodontics and cephalometric analysis, it was planned to advance the maxilla by $7 \mathrm{~mm}$ and impact it by $6 \mathrm{~mm}$. Intraoperatively, Trimble's modification of Lefort I osteotomy was performed to mobilize the maxilla and the necessary movements were accomplished. Adequate closure of the extracted third molar socket was achieved. The patient had an uneventful immediate postoperative recovery. At the end of the first post-operative week, the patient presented with a complaint of watery leakage from the right nostril, on intake of fluids. Clinical examination revealeda wound dehiscence on the maxillary right third molar region. The authors confirmed the presence of an oro-antral communication of about $5 \mathrm{~mm}$ on the region adjacent to maxillary tuberosity, where the right third molar was removed (Fig. 1). On the following day, the communication was closed in layers with buccal fat pad and buccal advancement flap (Fig. 2). The patient was followed up for three months and he had a satisfactory healing (Fig. 3). 


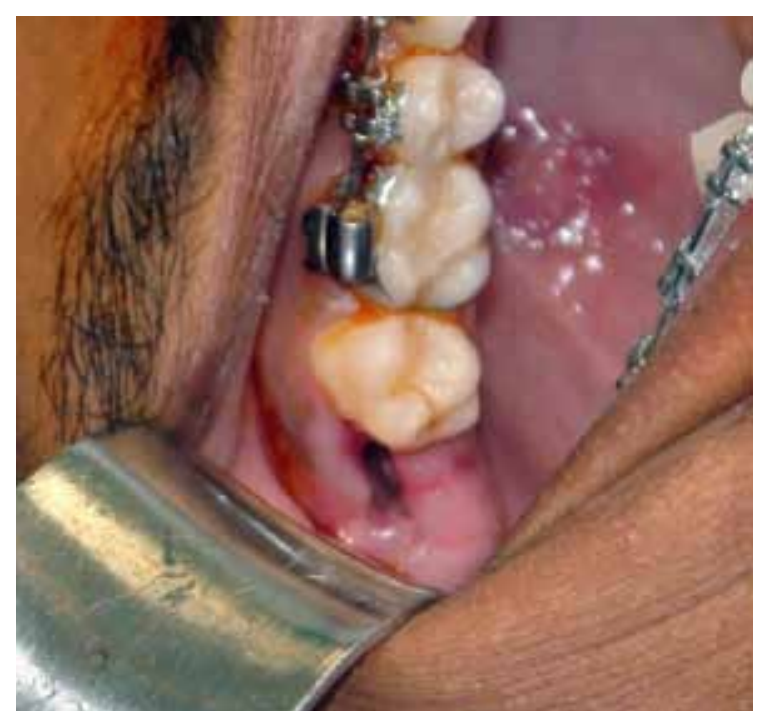

Fig. 1 Oro-antral communication on the right tuberosity area

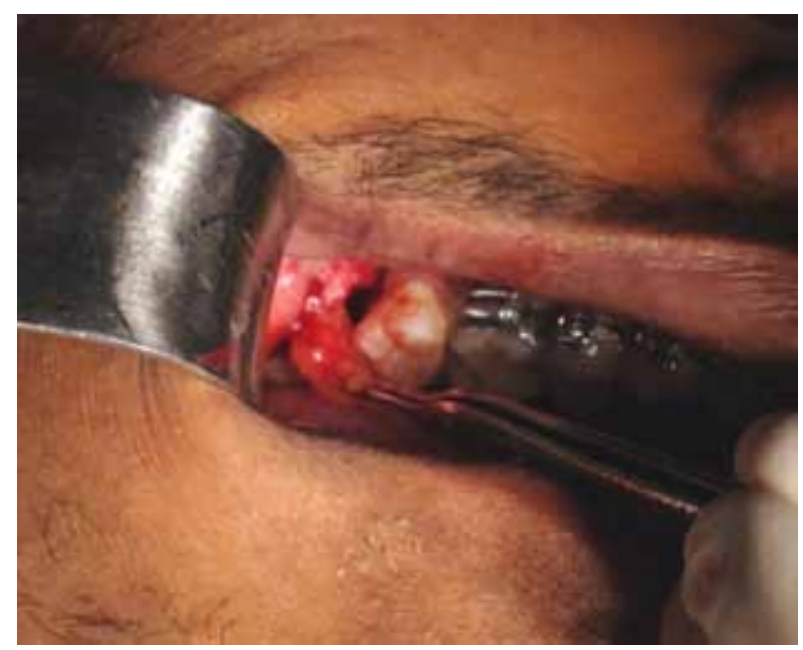

Fig. 2 Closure of communication with buccal fat pad

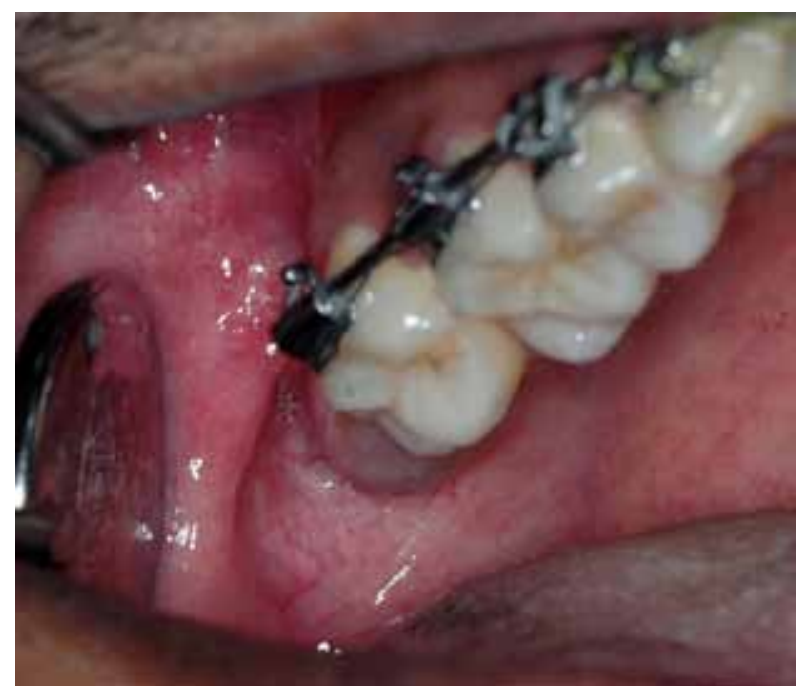

Fig. 3 Postoperative healing following closure of communication

\section{Discussion}

Since the first descriptions of Lefort I osteotomy by Wassmund ${ }^{[2]}$ and Schuchardt ${ }^{[3]}$, there had been suggestions of several modifications by various authors ${ }^{[4,5]}$. Trimble et al proposed a modification by advocating the placement of vertical posterior osteotomy cuts through the tuberosity. This technique has considerable advantages over the conventional technique as it is anatomically less hazardous, allows greater segmental mobility and also permits maintenance of a larger vascular pedicle ${ }^{[6]}$.

Lefort I osteotomies are associated with a varied number of complications. Occurrence of oro-nasal/ oro-antral fistulas are rare complications after Lefort I osteotomies. Steel et al reported that oro-nasal fistulas are more common than oro-antral fistulas ${ }^{[7]}$, specifically in anterior segmental osteotomies and Ho et al recorded an incidence rate of $5 \%$ for oro-nasal fistulas ${ }^{[8]}$. Midline osteotomies are more commonly associated with palatal tears due to the thin palatal mucosa and these are less likely to heal.

Khandelwal et al defines oro-antral fistula as an epithelialized pathological unnatural communication between the oral cavity and maxillary sinus ${ }^{[9]}$. Initial treatment of oro-antral fistula includes routine sinus management with decongestants, nasal spray, antibiotics and obturation of open fistulas by using a soft "suck down" material for shrinkage or elimination of fistula ${ }^{[10]}$.

Numerous surgical procedures have been recommended by various authors for the closure of oroantral fistula. These procedures maybe categorised into local flaps, distant flaps and tissue grafting.

The Rehrman buccal advancement flap is the most common method implemented in the closure of oroantral fistula. After debriding the epithelium, the defect is covered with a buccal mucoperiosteal advancement flap. The shape of the flap is trapezoid, with its base at the buccal sulcus to ensure maintenance of adequate blood supply. The major disadvantage of this technique is that it leads to reduction in the vestibular depth ${ }^{[11]}$.

The buccal pad of fat (Boule de Bichat) is a simple lobulated mass which is covered by a thin capsule and located inside the masticator spaces. Since Egyedi reported the use of buccal pad of fat in the closure of oro-antral fistula ${ }^{[12]}$, several authors have utilized them to a good effect ${ }^{[13,14,15]}$. The advantages of this technique 
include ease of harvesting, good epithelialization and a high success rate ${ }^{[9]}$.

Batra et al have demonstrated a double layer flap closure method wherein, a buccal fat pad flap was advanced to cover the oro-antral fistula, followed by a layer of buccal mucosal advancement flap over it ${ }^{[11]}$.

To the authors' knowledge, there is no published evidence of an oro-antral fistula in relation to maxillary third molar socket after Trimble's technique. The authors feel that despite adequate closure of the extraction site, the advancement at the site of third molar socket might have created more gap between the bone segments, predisposing to a larger communication. The authors performed a two-layer closure with buccal pad of fat and buccal advancement flap, which ensured excellent healing within a span of 2 weeks. The authors advocate that extreme care is necessary while suturing the third molar socket after osteotomies to negate the occurrence of such complications.

\section{Ethical Clearance: Nil}

Source of Funding: Meenakshi Academy of Higher Education and Research, Chennai, India

\section{Conflict of Interest: Nil}

\section{References}

1. Buchanan EP, Hyman CH. LeFort I osteotomy. InSeminars in plastic surgery 2013 Aug (Vol. 27, No. 3, p. 149). Thieme Medical Publishers.

2. Wassmund M. Lehrbuch der praktischen Chirurgie des Mundes und der Kiefer. H. Meusser; 1935.

3. SCHUHARDT K. Experiences with the surgical treatment of deformities of the jaws: prognathia, micrognathia and open bite. InInternational Society of Plastic Surgeons, Second Congress 1959 (Vol. 73). E \& S Livingstone.

4. Bennett MA, Wolford LM. The maxillary step osteotomy and Steinmann pin stabilization. Journal of oral and maxillofacial surgery. $1985 \mathrm{Apr}$ 1;43(4):307-11.

5. Kaminishi RM, Davis WH, Hochwald DA, Nelson N. Improved maxillary stability with modified LeFort I technique. Journal of Oral and Maxillofacial Surgery. 1983 Mar 1;41(3):203-5.

6. Trimble LD, Tideman H, Stoelinga PJ. A modification of the pterygoid plate separation in low-level maxillary osteotomies. Journal of Oral and Maxillofacial Surgery. 1983 Aug 1;41(8):5446.

7. Steel BJ, Cope MR. Unusual and rare complications of orthognathic surgery: a literature review. Journal of oral and maxillofacial surgery. $2012 \mathrm{Jul}$ 1;70(7):1678-91.

8. Ho MW, Boyle MA, Cooper JC, Dodd MD, Richardson D. Surgical complications of segmental Le Fort I osteotomy. British Journal of Oral and Maxillofacial Surgery. 2011 Oct 1;49(7):562-6.

9. Khandelwal P, Hajira N. Management of oroantral communication and fistula: various surgical options. World journal of plastic surgery. 2017 Jan;6(1):3.

10. Robl MT, Farrell BB, Tucker MR. Complications in orthognathic surgery: a report of 1000 cases. Oral and Maxillofacial Surgery Clinics. 2014 Nov 1;26(4):599-609.

11. Batra H, Jindal G, Kaur S. Evaluation of different treatment modalities for closure of oro-antral communications and formulation of a rational approach. Journal of maxillofacial and oral surgery. 2010 Mar 1;9(1):13-8.

12. Egyedi P. Utilization of the buccal fat pad for closure of oro-antral and/or oro-nasal communications. Journal of maxillofacial surgery. 1977 Jan 1;5:2414.

13. Tideman H, Bosanquet A, Scott J. Use of the buccal fat pad as a pedicled graft. Journal of Oral and Maxillofacial Surgery. 1986 Jun 1;44(6):43540.

14. Rapidis AD, Alexandridis CA, Eleftheriadis E, Angelopoulos AP. The use of the buccal fat pad for reconstruction of oral defects: review of the literature and report of 15 cases. Journal of oral and maxillofacial surgery. 2000 Feb 1;58(2):158-63.

15. Borgonovo AE, Berardinelli FV, Favale M, Maiorana C. Surgical options in oroantral fistula treatment. The open dentistry journal 2012; 6: 94 